J. Lake Sci. (湖泊科学) , 2007, 19(5) :599-603

http:// www. jlakes. org. E-mail: jlakes@ niglas. ac.cn

(C) 2007 by Journal of Lake Sciences

\title{
内陆盐沼湿地土壤碳氮磷剖面分布的季节动态特征"
}

\author{
白军红 ${ }^{1}$, 邓 伟 $^{2}$, 王庆改 ${ }^{3}$, 丁秋祎 ${ }^{1}$
}

(1: 北京师范大学环境学院, 水环境模拟国家重点实验室, 北京 100875)

(2: 水利部、中国科学院成都山地灾害与环境研究所, 成都 610041)

(3: 国家环境保护总局环境工程评估中心, 北京 100012)

摘 要: 本文以向海湿地为例探讨了内陆盐沼湿地土壤剖面中碳氮磷等生源要素的季节动态变化特征及其影响因素. 结 果表明, 内陆盐沼湿地土壤中有机碳、全氮和全磷含量与土壤深度之间存在显著负相关,在剖面中均表现为由表层向下层 其含量不断减少的趋势, 且具有明显的季节波动特征,除表层土壤碳氮含量随季节变化呈持续增加外,生源要素剖面分布 的季节变化基本表现为先减少后增加的趋势. 有机碳、全氮和全磷含量之间关系密切, 且三者受土壤粒度的影响都非常 显著. 土壤 $\mathrm{pH}$ 值仅与土壤有机碳之间存在显著的相关关系, 而对全氮和全磷含量的影响则不显著.

关键词: 内陆盐沼湿地;土壤剖面;生源要素;季节动态;影响因素;向海

\section{Seasonal dynamics of carbon, nitrogen and phosphorous in soil profiles from an inland salt marsh}

BAI Junhong ${ }^{1}$, DENG Wei ${ }^{2}$, WANG Qinggai ${ }^{3} \&$ DING Qiuyi ${ }^{1}$

(1: State Key Lab. of Water Envir. Simulation, School of Environment, Beijing Normal University, Beijing 100875 ,P. R. China)

(2: Institute of Mountain Hazards and Environment, Chinese Academy of Sciences, Chengdu 610041, P. R. China) (3: Appraisal Center of Envir. and Engineering, State Envir. Protection Administration, Beijing 100012,P. R. China)

Abstract: Wetlands are widely distributed in the northeast of China, serving as source, sink or transfer of most chemical matter. Owing to worse natural environment such as drought, water shortage and intense human activities, inland salt marshes were extensively developed in the west Songhuajiang-Nenjiang plain with high ecological frangibility, in which Xianghai wetland is one typical inland salt marsh located downstream of Huolin river basin, Jilin Province of China. Soil samples were collected in Xianghai wetland during four months (May, July, September and October) in 2001. The contents of soil organic carbon ( SOC), total nitrogen (TN), total phosphorous (TP), soil $\mathrm{pH}$ and soil particle sizes were measured in wetland soils in order to study influencing factors and seasonal dynamics of the life elements in soil profiles from inland salt marsh. Correlation analysis was carried out to show the relationships between SOC, TN, TP, soil pH, clay, silt and sand. Results showed that SOC, TN and TP contents were significantly negatively correlated with depth, and decreased from surface soils down to bottom soil layers in four months; the obvious seasonal dynamics of SOC, TN and TP contents in soil profiles were also observed and the seasonal dynamics of life elements in soil profiles generally showed the consistent changing trends of "increasing after decreasing" with the exception of continuous increase of SOC and TN contents in surface soils, There were significantly negative correlations between SOC, TN and TP, which were greatly influenced by soil clay, silt and sand contents; soil pH was significantly negatively correlated with SOC content, but weakly influenced TN and TP contents. Since soil nutrient contents are important determining factors of soil fertility, changes of which greatly influence productivity of wetland ecosystem, which can provide scientific basis for further studies of evolvement of soil 
quality, ecological restoration and sustainable management of wetlands in this region.

Keywords : Inland salt marsh; soil profiles; life elements; seasonal dynamics; influencing factors; Xianghai Wetland

在陆地生态系统中土壤是碳、氮、磷等生源要素的主要蓄积库之一, 在全球碳循环、氮循环和磷循环中 发挥着重要作用 ${ }^{[1]}$. 湿地作为地球表层的一个界面, 是岩石圈、生物圈、水圈、大气圈和人类圈相互联系的 重要纽带和多种运动形态物质体系的交汇场所, 承担着碳氮磷的源、汇或转化器的功能 ${ }^{[2-4]}$. 土壤有机碳 是气候变化的一种敏感指示物, 它能够用来指示湿地生态系统对气候变化的响应 ${ }^{[5]}$; 而氮磷则是湿地营养 水平指示物,在自然条件下,生物地球化学过程达到一种稳定状态,伴随着沉积物中养分的再循环以满足湿 地植物群落的需要. 目前对湿地土壤中碳氮磷的时空分布特征已有不少研究 ${ }^{[6-11]}$, 许多研究也已表明沼泽 湿地土壤生源要素含量在垂直分布上具有高度的空间异质性,且湿地不同土壤发生层的养分含量动态变化 显著,但上述研究大多停留在某一时期养分的空间分布格局 ${ }^{[2,7,9]}$ 和对不同土壤发生层养分的季节动态变 化研究上, 且主要集中在淡水湿地 ${ }^{[6-9]}$ 和滨海盐沼湿地 ${ }^{[10-11]}$, 而对内陆盐沼湿地生源要素剖面分布的季节 动态变化研究鲜有报道.

松嫩平原西部是我国内陆盐沼湿地的集中分布区, 是候鸟迁飞的重要驿站,但该区生态脆弱性强,盐碱化 和沙化严重, 导致湿地生产力不断下降,生物多样性减少, 呈现出严重退化的趋势. 而湿地土壤养分含量决定 土壤肥力的重要因素, 其动态变化显著影响着湿地生态系统的生产力. 因此, 研究盐碱湿地土壤养分的动态 变化规律, 可为定量评价该区湿地土壤质量演变阶段、方向以及寻求其主导影响因子研究提供科学支撑; 并可 通过人为调控关键影响因子, 不断改善土壤的营养状况, 实现提高湿地生态系统的净初级生产力和维持生物 多样性的目的,进而为该区退化湿地的生态恢复以及湿地的可持续性管理和保护提供理论指导和借鉴.

\section{1 材料与方法}

\section{1 研究区概况}

向海湿地位于吉林省通榆县西部的向海自然保护区内, 属于典型内陆盐沼湿地 (土壤 $\mathrm{pH}$ 值 $>8.3$ ), 被 列为国际重要湿地, 拥有湿地面积 $36100 \mathrm{hm}^{2}$, 包括水域面积 $12500 \mathrm{hm}^{2}$ 和芦苇沼泽面积 $23600 \mathrm{hm}^{2[12]}$. 该区 处于北温带大陆性季风气候区半干旱草原地带,年平均气温 $5.1^{\circ} \mathrm{C}$; 年平均降水量 $408.2 \mathrm{~mm}$, 多集中在 $7 、 8$ 月份; 年平均蒸发量 $1945 \mathrm{~mm}$, 约为降水量的 5 倍; 区内河流主要有霍林河、额穆泰河及洮儿河引水工程等 季节性河流,有向海水库、兴隆水库、尖底泡、付老文泡等水库及自然泡沼 20 多处. 研究区土壤类型为沼泽 土,植被以芦苇群落为主.

\section{2 样品的采集和测定}

2001 年分别在 5、7、9、10 月份采集典型样地土壤剖面样品. 每个月份重复采集 6 个土壤剖面,剖面深 度为 $100 \mathrm{~cm}$, 按每 $10 \mathrm{~cm}$ 为一层共分 10 个层次进行采集,所有土样带回实验室后自然风干,捡去石块、残根 等杂物,用球磨机磨碎,过 100 目笁,装袋备用待测. 四个月份所采集的土壤样品总计 240 个.

有机碳采用重铬酸钾容量法测定; 全氮采用凯氏定氮法测定; 全磷采用钼锑抗比色法测定 ${ }^{[13]} ; \mathrm{pH}$ 值 (土：水 $=1: 5)$ 采用电位法测定; 土壤粒度采用粒度分析仪测定.

\section{3 统计分析}

对不同月份土壤剖面中碳、氮、磷含量测定值进行方差分析 (ANOVA) 来检验它们之间的差异显著性; 采用 Pearson 相关系数来分析土壤理化性质之间的相关系数. 运用 Origin6. 0、SPSS10.0 软件包和 Excel2000 对数据进行统计分析及绘图.

\section{2 结果与讨论}

\section{1 土壤有机碳含量剖面分布的季节动态变化}

各月份土壤有机碳的剖面分布特征一致,均呈现由表层向下不断减少的总趋势(图 1a);30-40 cm 土 层以上各土层有机碳含量差异显著,但以下各土层有机碳含量相近,不存在显著差异 $(P<0.01)$; 土壤剖面 中有机碳含量具有明显的季节动态变化特征,除表层土壤有机碳含量随时间变化持续增长外,其它各层土 
(a) $\operatorname{SOC}(\%)$

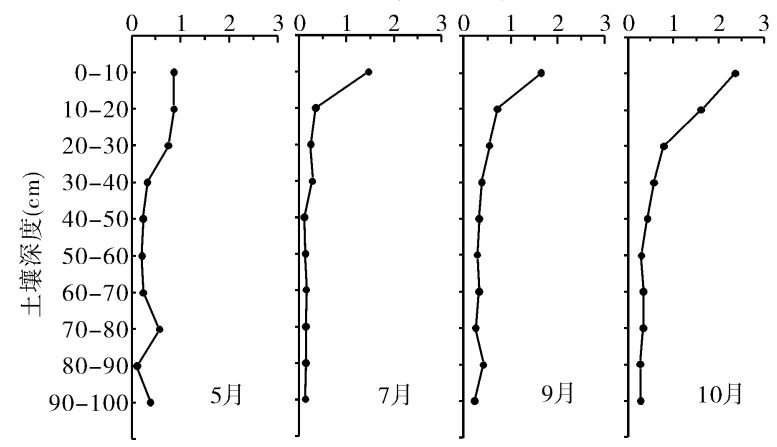

(b) $\mathrm{TN}(\mathrm{mg} / \mathrm{kg})$

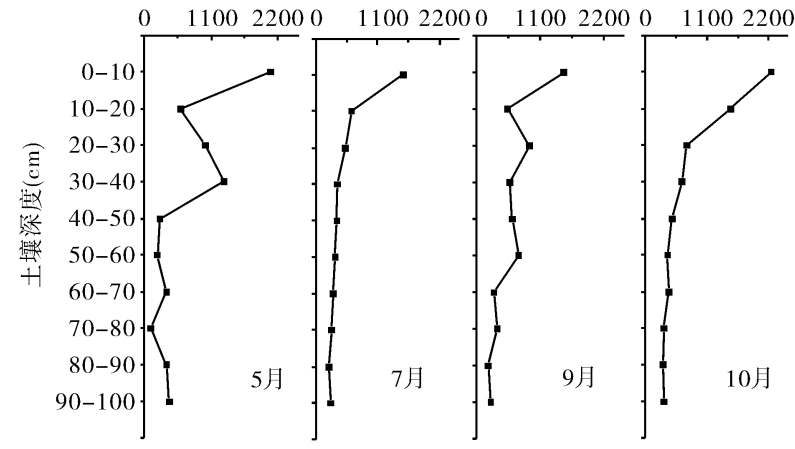

(c) $\mathrm{TP}(\mathrm{mg} / \mathrm{kg})$

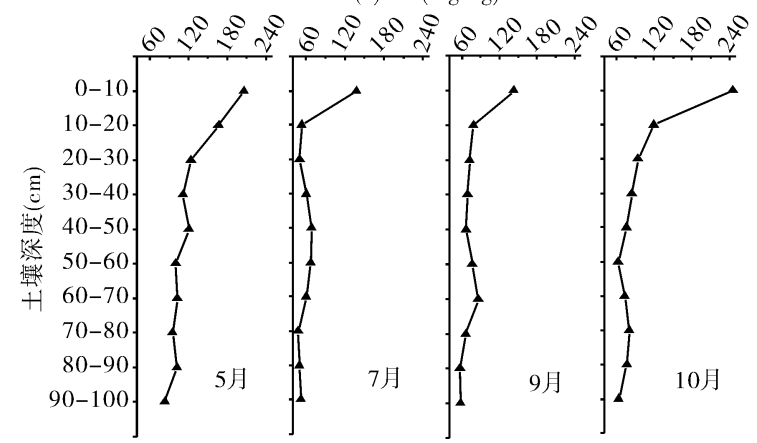

图 1 内陆盐沼湿地土壤有机碳 $(\mathrm{a})$ 、全氮 $(\mathrm{b})$ 、全磷 $(\mathrm{c})$ 剖面分布季节动态变化

Fig. 1 Seasonal dynamics of organic carbon contents(a), total nitrogen contents(b) and total phosphorous contents(c) in soil profiles from inland salt marsh

壤大都表现为先减少后增加的动态变化趋势. 表层土壤有机碳含量呈现持续增长与表层积累的枯落物不 断分解和凋落物累积量随植物生长节律变化呈指数增长 ${ }^{[14]}$ 密切相关; 其它土层在解冻期 (5 月份) 的有机 碳含量主要源于上一年份的累积,且冻融作用有助于有机碎屑的分解和碳矿化过程 ${ }^{[15]}$; 而 7 月份由于土壤 温度升高, 土壤微生物活性增强, 导致土壤有机质分解加速, 且碳消耗量增加 ${ }^{[6]}$; 同时由于近年气候干旱, 导致霍林河上游来水量不足,下游湿地旱化趋势明显, 研究区内基本无地表积水, 在很大程度上抑制了表土 层中可溶性有机碳的下渗 ${ }^{[9]}$. 随着芦苇的生长, 芦苇根系和根状茎充分发育固定了更多的碳, 植物根系分 泌物和死根的不断输人使 9 月份亚土层有机碳含量增加. 10 月份因气温下降, 植物生长停滞, 开始枯死, 促 进了有机碳的累积; 近地表土层 $(40 \mathrm{~cm}$ 以上) 有机碳含量增加趋势明显, 以下土层的有机碳含量变化不大, 这与芦苇根系主要分布在 $40 \mathrm{~cm}$ 以上土层和死根输人量的增加密切相关. 


\section{2 土壤全氮含量剖面分布的季节动态变化}

由图 $1 \mathrm{~b}$ 可知,土壤全氮的剖面分布特征与有机碳相一致,除 5 月份在 $30-40 \mathrm{~cm}$ 土层出现大的累积峰 外,基本呈现由表层向下不断减少的趋势,这支持白军红等 ${ }^{[2]}$ 所得碳氮消涨趋势一致的研究结论; $40-50$ $\mathrm{cm}$ 土层以上各土层全氮含量变化较大, 以下各土层含量相近, 差异不显著 $(P<0.05)$. 这是由于氮素的垂 直分布特征主要受制于土壤有机质的分布 ${ }^{[7]}$. 与有机碳相类似, 土壤全氮含量剖面分布的季节动态变化特 征也表现为除表层土壤呈现持续增加外,其它土层呈先减少后增加的变化趋势. 表层土壤全氮含量持续增 加的原因与有机碳相同. 其它土层 5 月份相对较高的氮素含量主要源于上一年份的累积, 因该时期土壤处 于解冻期,植物刚刚开始生长, 对氮素的吸收或输人量较少. 7 月份全氮含量下降是由于该时期植物生长旺 盛,植物所需氮素较多; 而且碱性土壤易导致氨挥发的气态氮损失 ${ }^{[16]}$;9 月份植物成熟,对养分的需求量减 少, 土壤氮素开始累积 ${ }^{[17]} ; 10$ 月份由于气温下降,植物开始枯死,有机氮分解速度下降,养分发生累积. 芦 苇根系的影响是导致 40-50 cm 以上土层全氮含量季节波动的一个重要因素, 因植物主要通过根系来吸收 和利用土壤中的有效态氮,且死亡根系的输人是增加根区土壤氮素含量的重要途径之一.

\section{3 土壤全磷含量剖面分布的季节动态变化}

土壤磷素也是植物生长发育必需的营养元素之一. 自然土壤中的全磷含量主要源于成土母质和动植 物残体归还量 ${ }^{[18]}$. 尽管速效磷是能被植物直接吸收利用的主要形态, 但土壤剖面中全磷含量的季节动态 变化也在一定程度上反映了植物的吸收利用状况. 图 1c 表明,与有机碳和全氮相类似,该区土壤全磷的剖 面分布特征也表现为由表层向下不断减少的趋势; $40-50 \mathrm{~cm}$ 以上各土层土壤全磷含量变化较大,以下各土 层含量相近, 差别不显著 $(P<0.05)$; 这与白军红等 ${ }^{[7]}$ 在研究莫莫格湿地土壤全磷的空间分布规律时所得 结论一致. 土壤全磷剖面分布的季节动态变化也表现为先减后增的明显变化趋势. 5 月份因土壤刚刚开始 解冻, 植物生长缓慢, 对磷素的吸收利用较少, 但进人 7 月份后植物生长旺盛, 对磷的吸收利用大幅度增加, 导致土壤全磷含量快速下降. 9 月份植物开始成熟, 对磷素的需求量减少,开始发生累积或被土壤胶体固 定; 10 月份因气候变冷, 植物逐渐枯死, 植物地上养分转移到地下,土壤中有机磷的分解速度下降, 同时凋 落物的累积也导致了土壤尤其是表层土壤磷素的增加. 同样, $40-50 \mathrm{~cm}$ 以上各土层磷含量的显著变化也 与植物根系的分布密切相关.

\section{4 土壤中生源要素、土层深度、土壤 $\mathrm{pH}$ 值及土壤粒度之间的相关关系}

土壤有机碳、全氮和全磷与土层深度呈极显著负相关关系 $(P<0.01$, 表 1$)$, 且三者之间在 $P<0.01$ 水 平上显著正相关. 白军红等 ${ }^{[2]}$ 在流域尺度上研究沼泽湿地碳氮磷的空间分布特征时也发现三者之间存在 显著的相关性. 土壤有机碳、全氮和全磷与粉粒和粘粒之间存在极显著正相关关系 $(P<0.01)$, 与砂粒呈极 显著负相关 $(P<0.01)$, 表明土壤颗粒越细, 质地越粘重, 土壤碳氮磷的含量越高, 这是由于粘粒的含量直 接影响土壤的通气性, 从而影响微生物的活动所致 ${ }^{[19]}$. 土壤 $\mathrm{pH}$ 值与有机碳在 $P<0.05$ 水平上显著负相 关,这与白军红等 ${ }^{[2]}$ 的研究结论一致,但与土壤全氮和全磷含量之间的相关关系则未达到显著性水平; 表 明高 $\mathrm{pH}$ 值可降低土壤的储碳能力, 而对土壤储氮和储磷能力的影响则不显著.

表 1 土壤生源要素与土壤深度、pH 值及土壤粒度之间的相关系数矩阵 ${ }^{1)}$

Tab. 1 Matrix of correlation coefficients between life elements, soil depth, pH and particle sizes

\begin{tabular}{ccccccccc}
\hline & $\begin{array}{c}\text { 深度 } \\
(\mathrm{cm})\end{array}$ & $\begin{array}{c}\text { 有机碳 } \\
(\%)\end{array}$ & $\begin{array}{c}\text { 全氮 } \\
(\mathrm{mg} / \mathrm{kg})\end{array}$ & $\begin{array}{c}\text { 全磷 } \\
(\mathrm{mg} / \mathrm{kg})\end{array}$ & $\mathrm{pH}$ 值 & $\begin{array}{c}\text { 砂粒 } \\
(\%)\end{array}$ & $\begin{array}{c}\text { 粉粒 } \\
(\%)\end{array}$ & $\begin{array}{c}\text { 粘粒 } \\
(\%)\end{array}$ \\
\hline 有机碳 $(\%)$ & $-0.672^{* *}$ & 1.000 & & & & & & \\
全氮 $(\mathrm{mg} / \mathrm{kg})$ & $-0.660^{* *}$ & $0.764^{* *}$ & 1.000 & & & & \\
全磷 $(\mathrm{mg} / \mathrm{kg})$ & $-0.563^{* *}$ & $0.752^{* *}$ & $0.797^{* *}$ & 1.000 & & & \\
$\mathrm{pH}$ 值 & 0.209 & $-0.320^{*}$ & -0.276 & -0.261 & 1.000 & & \\
砂粒 $(\%)$ & 0.262 & $-0.623^{* *}$ & $-0.622^{* *}$ & $-0.652^{* *}$ & 0.246 & 1.000 & & \\
粉粒 $(\%)$ & -0.112 & $0.505^{* *}$ & $0.498^{* *}$ & $0.571^{* *}$ & -0.224 & $-0.975^{* *}$ & 1.000 & \\
粘粒 $(\%)$ & $-0.430^{*}$ & $0.727^{* *}$ & $0.733^{* *}$ & $0.706^{* *}$ & -0.256 & $-0.961^{* *}$ & $0.874^{* * *}$ & 1.000 \\
\hline
\end{tabular}

1 ) 样品数 $n=40 ;{ }^{* *}$ 显著性水平 $P<0.01, *$ 显著性水平 $P<0.05$. 


\section{3 参考文献}

[1] 陈泮勤, 孙成权. 国际全球变化研究核心计划 (二). 北京: 气象出版社, 1994: 131-151.

[2] 白军红, 邓 伟, 朱颜明等. 霍林河流域湿地碳氮空间分布特征及生态效应. 应用生态学报, 2003, 14 (9) : $1494-1498$.

[3] Mitsch W J, Gosselin J G. Wetlands. New York: Van Nostrand Reinhold Company Inc, 2000.

[4] Bulatnikova I V, Makarov M I, Malysheva T I et al. Organic nitrogen mineralization and nitrification in meadow alpine soils of the northeastern Caucasus. Moscow University Soil Science Bulletin, 2003, 58(2) : 9 -15 .

[5] Clair T A, Arp P, Moore T R et al. Gaseous carbon dioxide and methane, as well as dissolved organic carbon losses from a small temperate wetland under a changing climate. Environmental Pollution, 2002, 116: $\mathrm{S} 143$ - S148.

[6] 张金波, 宋长春, 杨文燕. 小叶章湿地表土水溶性有机碳季节动态变化及影响因素分析. 环境科学学 报,2005,25(10): $1397-1402$.

[7] 白军红, 邓 伟, 张玉霞. 莫莫格湿地土壤氮磷空间分布规律研究. 水土保持学报, 2001, 15(4):79 -81 .

[8] 杨永兴, 王世岩, 何太蓉等. 三江平原湿地生态系统 $\mathrm{P} 、 \mathrm{~K}$ 分布特征及季节动态研究. 应用生态学报, $2001,12(4): 522-526$.

[9] Bai J, Ouyang H, Deng W et al. Spatial distribution characteristics of organic matter and total nitrogen of marsh soils in river marginal wetlands. Geoderma, 2005, 124:181 - 192.

[10] 李任伟,李 禾,李 原. 黄河三角洲沉积物重金属、氮和磷污染研究. 沉积学报, 2001, 19(4):622 -629 .

[11] Zhou J L, Wu Y, Zhang J et al. Carbon and nitrogen composition and stable isotope as potential indicators of source and fate of organic matter in the salt marsh of the Changjiang Estuary, China. Chemosphere, 2006, 65(2):310-317.

[12] 赵魁义. 中国沼泽志. 北京: 科学出版社, 1999: $255-260$.

[13] 鲁如坤. 土壤农业化学分析方法. 北京: 中国农业科技出版社, 1999: $107-147$.

[14] 白军红. 向海沼泽湿地氮素生物地球化学过程研究. 中国科学院东北地理与农业生态研究所 [学位 论文], 2003.

[15] Grofman P M, Driscoll C T, Fahey T J et al. Effects of mild winter freezing on soil nitrogen and carbon dynamics in a northern hardwood forest. Biogeochemistry, 2001, 56: 215 - 238 .

[16] 朱兆良,文孝启. 中国土壤氮素. 江苏: 江苏科学技术出版社, 1992 .

[17] 白军红, 邓 伟, 欧阳华等. 吉林向海沼泽湿地土壤氮素的剖面分布. 湖泊科学, 2004, 16 (4): 377 -380 .

[18] 戎郁萍, 韩建国,王 培等. 放牧强度对草地土壤理化性质的影响. 中国草地, 2001, 23(4):41-47.

[19] Oades J M. The retention of organic matter in soil. Biogeochemistry, 1988, 43 : 35 - 70. 